J. Lake Sci. (湖泊科学), 2021, 33(3): 819-829

DOI 10. 18307/2021. 0321

(c) 2021 by Journal of Lake Sciences

\title{
三峡水库蓄水后下荆江河段典型洲滩调整机理”
}

\author{
杨绪海 ${ }^{1}$, 熊海滨 $^{1}$, 李义 $^{1 * *}$, 李思璇 $^{2}$ \\ (1: 武汉大学水资源与水电工程科学国家重点实验室, 武汉 430072) \\ (2: 长江水利委员会水文局,武汉 430010)
}

\begin{abstract}
摘 要: 三峡工程运行后长江中下游河道洲滩普遍冲刷萎缩,航道条件极不稳定. 为探究影响洲滩演变的主控因素,采用 近期水文、泥沙和地形观测资料,以下荆江铁铺水道广兴洲边滩为例,分析了边界条件、水沙过程及整治工程等因素对洲 滩调整特征的影响程度. 结果表明: 洲滩组成中的细沙 $(0.125 \mathrm{~mm}<d<0.25 \mathrm{~mm})$ 占比较大, 抗冲性较弱, 是滩体冲刷的前提 条件. 三峡工程运行后广兴洲边滩年际间呈冲刷萎缩趋势, 水沙条件变化是洲滩变形的主导因素, 滩体冲淤变化与漫滩 流量 $\left(Q>15000 \mathrm{~m}^{3} / \mathrm{s}\right)$ 有一定关系, 其持续时间越长, 一般表现为滩体面积越小; 汛期悬移质分组沙输移过程中, 细沙的大 幅减少导致边滩萎缩明显, 其影响程度比漫滩流量更大. 滩体冲淤变形特征与前 3 年漫滩流量下平均水流冲刷强度的相 关性最好. 守护工程实施后, 漫滩流量下平均水流冲刷强度仍然较大, 但滩体后退趋势得以抑制且小幅淤积, 工程效果得 以充分发挥.
\end{abstract}

关键词: 洲滩演变;水沙过程;守护工程;漫滩流量;水流冲刷强度;三峡水库

\section{Adjustment mechanism of the typical sandbars in the lower Jingjiang River after the im- poundment of the Three Gorges Reservoir*}

\author{
Yang Xuhai ${ }^{1}$, Xiong Haibin ${ }^{1}$, Li Yitian ${ }^{1 * *} \&$ Li Sixuan $^{2}$ \\ (1: State Key Laboratory of Water Resources and Hydropower Engineering Science, Wuhan University, Wuhan 430072, P.R. \\ China) \\ (2: Bureau of Hydrology, Changjiang Water Resources Commission, Wuhan 430010, P.R. China)
}

\begin{abstract}
After the operation of the Three Gorges Project (TGP), the sandbars in the middle and lower reaches of the Yangtze River were scoured and atrophic mostly, resulting in the channel conditions extremely unstable. In order to explore the dominant factors affecting the evolution of sandbars, combined with the recent hydrologic, sediment, and topographic observation data, the Guangxingzhou point bar of Tiepu reach of the lower Jingjiang is taken as an example to analyze the adjustment characteristics of sandbars and their response to boundary conditions, flow and sediment processes and remediation projects. The results show that most of the fine sand in the composition of the sandbars are weak in resistance to erosion, which is the precondition for the erosion of sandbars. After the operation of the TGP, the Guangxingzhou point bar has a tendency of erosion and shrinkage year by year. The change of flow and sediment conditions is the dominant factor of the deformation of the sandbars, there is a relationship between the variation of the Guangxingzhou point bar and over-bar discharge $\left(Q>15000 \mathrm{~m}^{3} / \mathrm{s}\right)$, and the longer days last, generally the smaller the sandbar is. The amount of bed material in flood season is greatly reduced, especially the decrease of fine sand $(0.125 \mathrm{~mm}<d<$ $0.25 \mathrm{~mm}$ ), making the point bar shrink significantly, the impact of which is greater than over-bar discharge. There is a significant correlation between the area of the Guangxingzhou point bar and the average fluvial erosion intensity of over-bar disscharge in the first three years. After the implementation of the revetment project, the receding trend of the point bar is restrained, the area is stable and increased slightly, indicating that the revetment project has been fully effective.
\end{abstract}

Keywords: Evolution of point bar; flow and sediment process; revetment project; over-bar discharge; average fluvial erosion intensity; Three Gorges Reservoir

* 2020-04-24 收稿; 2020-09-03 收修改稿.

国家重点基础研究发展计划项目(2010CB429002)资助.

** 通信作者;E-mail:ytli@ whu.edu.cn. 
冲积河流河床上通常布满各种形式的成型淤积体, 例如边滩、心滩等, 作为河流基本组成单元, 其演变 形式对于河势稳定具有重要意义. 三峡水库运行后, 坝下游滩槽格局出现了趋势性调整, 长江中下游不同高 程滩体冲淤部位及幅度存在显著差异, 洲滩整体呈冲刷萎缩之势 ${ }^{[1-3]}$, 尤其是蜿蜒曲折、洲滩密布且抗冲性 较弱的下荆江沙质河段, 冲刷强度历来较大 ${ }^{[4-5]}$. 为缓解防洪压力, 荆江河段两岸已受人工控制, 由于河宽受 限, 河道内滩体规模受发展空间制约而易于发生冲淤变形. 过渡放宽段因冲滩泥沙下移而频发碍航问题, 疏 浚后时而复发,已成为水利、航道部门关注与治理的重点. 因此, 研究下荆江河段的洲滩演变特征及机理尤 为重要和紧迫.

大型水库修建后, 受水库调蓄模式、区域气候环境、初始边界条件等影响, 不同河流上洲滩变化表现各 异: 三峡水库下游洲滩呈中低滩趋势性冲刷, 高滩滩缘崩退趋势 ${ }^{[6]}$, 其他水库下游河道甚至存在多数洲滩已 经消失的现象 ${ }^{[7]}$. 相反, 水库影响下粗沙的补给和水流能量的降低可导致下游河道滩体的形成和发展 ${ }^{[8]}$, 丹 江口水库下游小滩普遍合并为大滩 ${ }^{[9]}$. 而对于荆江河段, 洲滩普遍冲刷萎缩已基本达成共识 ${ }^{[2-3]}$, 其河段内 洲滩冲淤消长及位置迁移等变化, 将会对河势变化、防洪安全、通航条件、生态环境等造成一系列的影 响 ${ }^{[10-12]}$. 在洲滩调整机理方面, 已有研究 ${ }^{[11,13-18]}$ 多从主流大小、特征流量级持续时间、含沙量大小等角度分 析洲滩冲淤的演变特性,亦有学者 ${ }^{[3]}$ 认为河道平面形态是影响洲滩变形的重要因素. 可见, 水库下游洲滩冲 淤调整对水沙条件变化十分敏感, 且影响因素十分复杂, 仅仅关注某一影响因子,均难以准确描述冲积河流 洲滩变化对外界因素变化的响应特征. 因此,各因素对洲滩变化的影响程度到底如何有待系统研究.

下荆江铁铺顺直河段作为长江中游碍航河段之一, 受水沙条件影响较大, 滩体年内冲淤消长, 位置变化 频繁, 对河势稳定及通航条件影响较大, 受到航道部门及工程界广泛关注. 广兴洲边滩既有沙质河床众多洲 滩普遍冲刷的共性变化特征, 又兼具顺直边滩缓慢下移的演变特点, 极具研究的典型性和代表性. 为此, 本 文以下荆江铁铺水道广兴洲边滩为例, 采用近期观测资料, 在漫滩流量持续作用时间的基础上考虑分组沙 输移特性, 探究了三峡水库蓄水前后及航道整治工程实施前后洲滩演变特征及其内在机理, 以期为长江中 下游航道整治提供参考.

\section{1 研究区域}

铁铺水道上起四十丈、下迄新堤子, 全长约 $12 \mathrm{~km}$, 水道进口相对较窄, 宽度为 $700 \mathrm{~m}$, 下游河道略有放 宽, 盐船套及新堤子处河道宽度约为 $1200 \mathrm{~m}$. 上游约 $26 \mathrm{~km}$ 处设监利水文站, 下游约 $32 \mathrm{~km}$ 处设城陵矶水文 站. 广兴洲边滩位于水道右岸侧, 是枯水期出露的长顺直低矮型边滩, 滩面几乎无植被生长, 其滩体年际间 冲淤变化频繁, 给通航、取水等带来一系列问题. 为约束边界条件、提高水流冲刷能力, 2014 年汗前在广兴洲 边滩上段建设 4 条护滩带, 长度分别为 $380 \mathrm{~m}$ (勾头长 $150 \mathrm{~m}$ )、294 m、348 m、503 m(勾头长 $150 \mathrm{~m}$ ), 守护宽 度均为 $180 \mathrm{~m}$, 并对护滩带根部进行守护, 护岸长度为 $1960 \mathrm{~m}$. 水文 $1^{\#} 、 2^{\#} 、 3^{\#}$ 断面分别位于滩头进口处、滩体 处、滩尾出口河道内 (图 1).

\section{2 资料和方法}

\section{1 资料}

水沙资料采用三峡水库蓄水前 $(1951-2002$ 年) 和蓄水后 $(2003-2016$ 年) 监利站日均流量、含沙量和 水位资料,来自于长江水利委员会水文局. 河床地形资料采用蓄水前 1981 年、1997 年、2000 年以及蓄水后 2003 年、2005-2010 年、2012 年、2014-2017 年 1:10000 观测资料,同时采用了局部断面水文以及床沙级配 资料, 以上资料来源于长江航道部门.

\section{2 方法}

2.2.1 数据处理方法 采用铁铺水道的实测地形资料, 并结合监利水文站逐日水位过程对洲滩露出水面部分 (黄海高程航行基面以上) 数据进行处理, 以获取三峡水库运用前后典型洲滩的滩体形态 (如最大洲长、最大 洲宽、滩顶高程) 及面积资料. 洲滩形态数据通过 CAD 软件获取. 为尽可能排除不同月份下水位不同造成的 误差, 统一采取汛后枯水期 ( 12 月一次年 3 月, 此时水位相差较小) 的数据资料, 优先采用次年数据来反映上 年水沙过程后的形态特征. 若资料缺乏, 则采用 12 月份数据, 其中 2003 年例外, 由于该年数据源较少, 以 11 

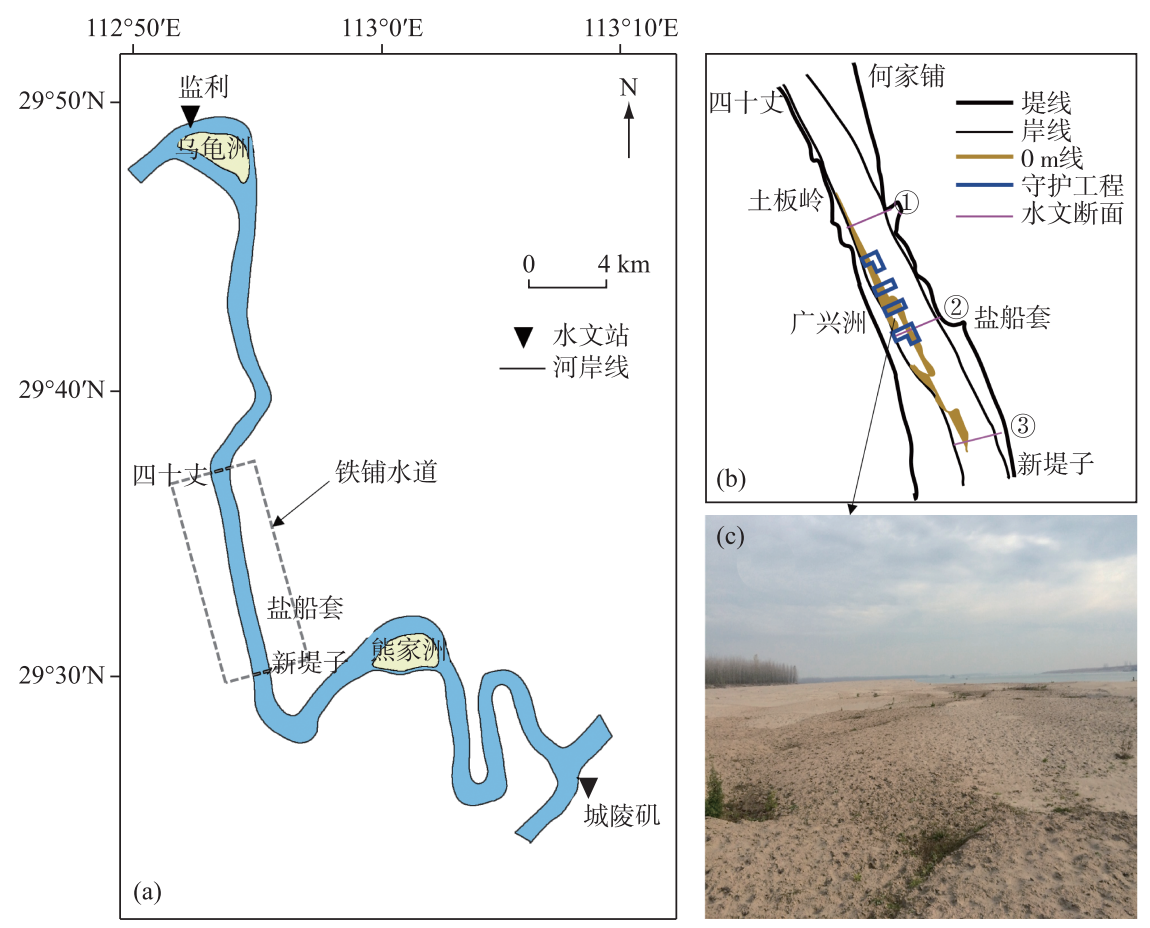

图 1 研究区域位置及滩面实景

Fig.1 Location and real scene of the study area

月份数据代替.

2.2.2 泥沙起动流速 泥沙颗粒大小不一, 受重力或粘结力作用, 其起动与沉降特性不同, 水流对其携带程度 有所差异. 泥沙起动与沉降常以起动流速做表征, 水流动力大小常以断面流速做表征, 以两者大小来判断洲 滩组成中泥沙可动性强弱. 参考已有研究 ${ }^{[19]}$, 将河床组成中泥沙按特定粒径大小进行分组, 划分为 $d<0.031$ $\mathrm{mm}$ 的中粉沙及黏土、 $0.031 \mathrm{~mm}<d<0.062 \mathrm{~mm}$ 的粗粉沙、 $0.062 \mathrm{~mm}<d<0.125 \mathrm{~mm}$ 的极细沙、 $0.125 \mathrm{~mm}<d<0.25$ $\mathrm{mm}$ 的细沙 $0.25 \mathrm{~mm}<d<0.5 \mathrm{~mm}$ 的中沙, $0.5 \mathrm{~mm}<d<1.0 \mathrm{~mm}$ 的粗沙和 $1.0 \mathrm{~mm}<d<2.0 \mathrm{~mm}$ 的极粗沙共 7 组. 各 粒径组泥沙的起动流速按张瑞瑾非均匀沙起动流速公式 ${ }^{[20]}$ 计算:

$$
U_{\mathrm{c}}=\left(\frac{h}{d}\right)^{0.14}\left(17.6 \frac{\gamma_{\mathrm{s}}-\gamma}{\gamma} d+6.05 \times 10^{-7} \frac{10+h}{d^{0.72}}\right)^{1 / 2}
$$

式中, $U_{\mathrm{c}}$ 为起动流速, $\mathrm{m} / \mathrm{s} ; h$ 为水深, $\mathrm{m} ; d$ 为泥沙粒径, $\mathrm{mm} ; \gamma_{\mathrm{s}}$ 为泥沙重度, $\mathrm{N} / \mathrm{m}^{3} ; \gamma$ 为水的重度, $\mathrm{N} / \mathrm{m}^{3}$.

2.2.3 平均水流冲刷强度 荆江河段在汛期 (5-10 月) 水沙集中输移现象明显, 在低含沙水流河段, 可采用 汛期平均水流冲刷强度 $F$ 来表征汛期内冲刷特征的水沙条件 ${ }^{[21]}$ :

$$
F=\frac{1}{N} \sum_{j=1}^{N}\left(Q_{j}^{2} / S_{j}\right) / 10^{8}
$$

式中, $Q_{j}$ 为汛期日均流量, $\mathrm{m}^{3} / \mathrm{s} ; S_{j}$ 为汛期日均含沙量, $\mathrm{kg} / \mathrm{m}^{3} ; N$ 为汛期时间, $\mathrm{d}$.

本文把影响洲滩冲刷变形的漫滩流量作为主要影响因素, 并考虑了水流持续时间和含沙量, 以反映漫 滩流量下平均水流冲刷强度:

$$
F_{\mathrm{T}}=\frac{1}{N} \sum_{j=1}^{N}\left(Q_{\mathrm{t},}^{2} / S_{\mathrm{t},}\right) / 10^{8}
$$

式中, $N$ 为漫滩流量持续作用的总时间, $\mathrm{d} ; Q_{\mathrm{t}}$ 为漫滩流量下日均流量, $\mathrm{m}^{3} / \mathrm{s} ; S_{\mathrm{t}}$ 为漫滩流量下日均悬移质含沙 量, $\mathrm{kg} / \mathrm{m}^{3}$. 
河床调整对水沙变化有滞后响应, 还需考虑前期累积效应 ${ }^{[22-23]}$. 因此前 $N$ 年漫滩流量下平均水流冲刷 强度可表示为:

$$
F_{\mathrm{T}_{N}}=\frac{1}{N} \sum_{i=1}^{N} F_{\mathrm{T}_{i}}
$$

式中, $F_{\mathrm{T}}$ 为第 $i$ 年漫滩流量下平均水流冲刷强度.

\section{3 洲滩形态调整}

\section{1 平面形态变化}

3.1 .1 年际演变特点 三峡水库蓄水前, 广兴洲边滩整体冲刷下移, 但受水沙条件影响, 年际间冲而复淤. 1981 年后滩体头部冲刷切割, 1997 年滩体冲退, 面积大幅减小, 2000 年滩体得以淤积恢复, 滩头上移,期间 滩体变化极不稳定. 2003 年以来边滩不断冲刷后退, 面积萎缩; 2008 年滩头冲退 $330 \mathrm{~m}$, 滩体面积萎缩了 $8.5 \%$; 2014 年相比 2008 年滩头进一步冲退 $1130 \mathrm{~m}$, 滩体面积仅为 2003 年的 $72.6 \%$, 最大滩宽位置也相应下 移(表 1). 2014 年守护工程实施后, 滩体稳定呈微淤上移趋势, 工程发挥了一定效果. 2015 年与 2014 年相 比, 滩头上移约 $600 \mathrm{~m}$, 至 2017 年滩体面积增加了 $15.7 \times 10^{4} \mathrm{~m}^{2}$, 增幅达 $15.3 \%$, 最大滩宽增加 $22.4 \mathrm{~m}$ (图 2 ). 3.1 .2 年内演变特点 广兴洲边滩在年内水文过程中遵循“涨冲落淤” 的演变规律. 如图 2 所示, 2009 年 39 月滩体面积冲刷缩小近 $30 \times 10^{4} \mathrm{~m}^{2}$, 至 11 月滩体面积回淤至 3 月相同水平, 滩体长度相比 3 月增加 274.8 $\mathrm{m}$,最大滩宽减少 $35.5 \mathrm{~m}$, 滩顶高程略有增加.

\section{表 1 三峡水库蓄水前后广兴洲边滩滩体特征值 ${ }^{*}$}

Tab.1 Characteristic values of the Guangxingzhou point bar before and after the impoundment of the Three Gorges Reservoir

\begin{tabular}{|c|c|c|c|c|c|c|c|c|c|}
\hline $\begin{array}{l}\text { 测量 } \\
\text { 时间 }\end{array}$ & $\begin{array}{c}\text { 面积/ } \\
\left(\times 10^{4} \mathrm{~m}^{2}\right)\end{array}$ & $\begin{array}{c}\text { 最大 } \\
\text { 滩长/m }\end{array}$ & $\begin{array}{c}\text { 最大 } \\
\text { 滩宽/m }\end{array}$ & $\begin{array}{c}\text { 滩顶 } \\
\text { 高程/m }\end{array}$ & $\begin{array}{l}\text { 测量 } \\
\text { 时间 }\end{array}$ & $\begin{array}{c}\text { 面积/ } \\
\left(\times 10^{4} \mathrm{~m}^{2}\right)\end{array}$ & $\begin{array}{c}\text { 最大 } \\
\text { 滩长/m }\end{array}$ & $\begin{array}{c}\text { 最大 } \\
\text { 滩宽/m }\end{array}$ & $\begin{array}{l}\text { 滩顶 } \\
\text { 高程/m }\end{array}$ \\
\hline 1998 年 10 月 & 190.54 & 4612.1 & 696.4 & 22.80 & 2009 年 11 月 & 125.15 & 3821.6 & 502.3 & 22.59 \\
\hline 2003 年 11 月 & 141.20 & 3738.1 & 451.4 & 22.60 & 2010 年 1 月 & 115.64 & 3723.6 & 491.4 & 22.59 \\
\hline 2005 年 11 月 & 139.62 & 4401.0 & 725.0 & 22.49 & 2012 年 2 月 & 104.77 & 2684.5 & 560.8 & 23.01 \\
\hline 2006 年 3 月 & 128.18 & 4025.0 & 600.6 & 22.39 & 2014 年 2 月 & 102.20 & 2533.2 & 535.8 & 22.80 \\
\hline 2007 年 3 月 & 102.88 & 3112.6 & 611.6 & 23.49 & 2015 年 1 月 & 73.02 & 2313.5 & 454.7 & 23.40 \\
\hline 2008 年 3 月 & 130.17 & 3777.0 & 586.0 & 23.29 & 2016 年 2 月 & 86.06 & 2869.6 & 455.5 & 23.90 \\
\hline 2009 年 3 月 & 125.56 & 3546.8 & 537.8 & 21.89 & 2017 年 3 月 & 102.82 & 3109.2 & 477.1 & 23.75 \\
\hline 2009 年 9 月 & 96.77 & 2663.6 & 494.2 & 22.39 & & & & & \\
\hline
\end{tabular}

* 滩体特征数据资料以黄海高程 $19.2 \mathrm{~m}$ 等高线统计得出.

\section{2 典型断面调整与航道条件变化}

如图 3 所示, 2002-2012 年 $1^{\#}$ 断面形态总体呈冲刷之势, 洲头前侧总体冲深, 河槽右侧冲淤交替变化. 2002 年通航条件较差, $3 \mathrm{~m}$ 等深线下航宽 (以下称航宽) 仅为 $70 \mathrm{~m} .2008$ 年航宽增加至 $328 \mathrm{~m}$, 之后伴随滩体 冲退, 2012 年航槽中心处淤高 $2.5 \mathrm{~m}$ 左右, 范围达 $200 \mathrm{~m}$ 左右, 航宽减少了 $67.4 \mathrm{~m} .2014$ 年后滩体稳定且小 幅淤积, 河槽断面形态冲刷变深, 2017 年航宽达 $591.3 \mathrm{~m}$, 航道条件大幅提升. 2002-2008 年 $2^{\#}$ 断面滩体右 侧冲刷严重, 滩顶高程降低 $2 \mathrm{~m}$ 左右, 伴随 2012 年滩顶高程进一步冲刷降低, 深槽有所淤积, 淤积深度 $1.5 \mathrm{~m}$ 左右, 航宽减少 38.1 m. 2014 年后, 滩顶高程淤高至 23.7 m, 滩宽也略有增加, 2017 年航宽相比 2012 年增加 了 $78 \mathrm{~m}$.

\section{4 洲滩调整影响因素}

三峡水库蓄水后, 水沙量及过程改变引起下游河道普遍冲刷 ${ }^{[24]}$, 洲滩形态出现响应性调整, 其冲淤变化 主要受河床边界条件、水沙过程变化、整治工程等因素影响. 

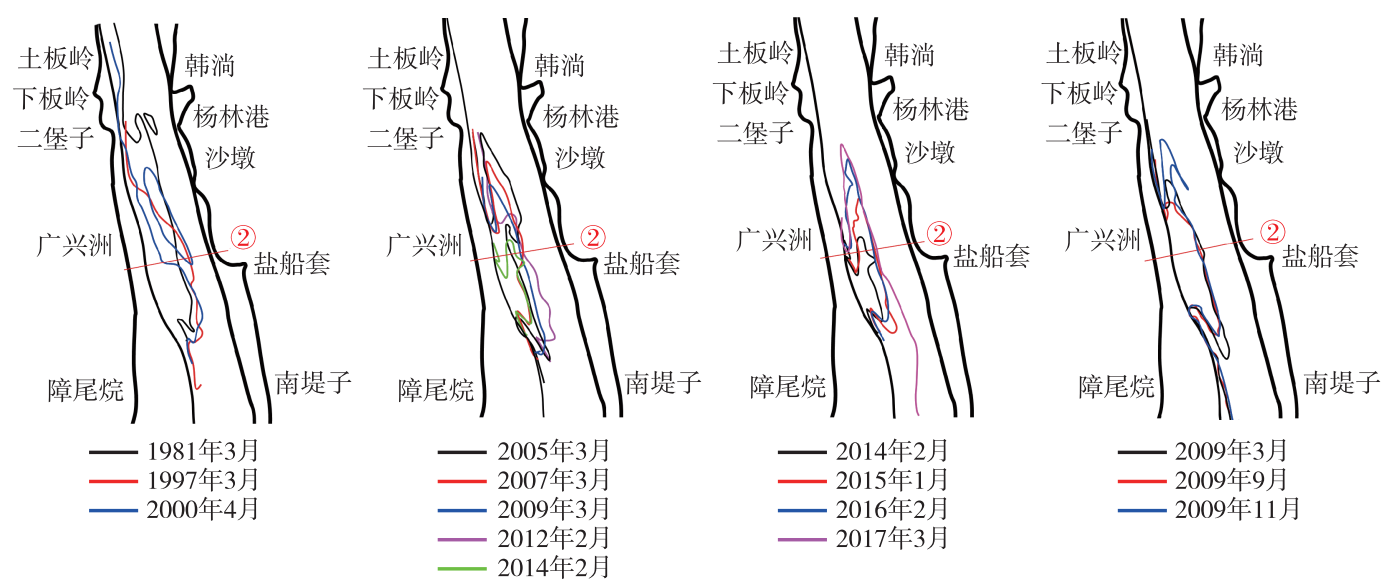

图 2 广兴洲边滩年际与年内变化

Fig.2 Intra-annual and inter-annual variation of the Guangxingzhou point bar
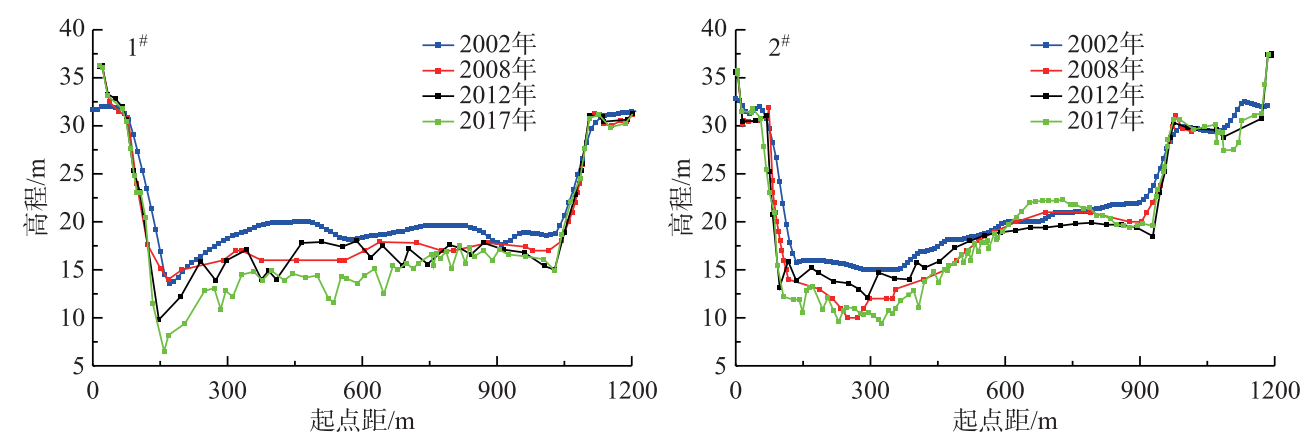

图 3 广兴洲边滩 $1^{\#}$ 与 $2^{\#}$ 断面年际变化

Fig.3 Annual variation of $1^{\#}$ and $2^{\#}$ cross section profiles of the Guangxingzhou point bar

\section{1 边界条件影响}

长江中下游河床由非均匀沙组成, 其河床组成为二元结构, 且洲滩、河槽泥沙组成存在差异, 洲滩粒径 组成比河床细 ${ }^{[25-26]}$. 由 $2^{\#}$ 断面上不同测点的级配变化 (图 4) 可知, 2014 年洲滩颗粒主要由 $0.125 \sim 0.36 \mathrm{~mm}$ 粒径组泥沙组成, 其中细沙 $(0.125 \mathrm{~mm}<d<0.25 \mathrm{~mm})$ 占比 $60 \% \sim 80 \%$, 中沙 $(0.25 \mathrm{~mm}<d<0.5 \mathrm{~mm})$ 的 $0.25 \mathrm{~mm}<$ $d<0.36 \mathrm{~mm}$ 泥沙组占比 $20 \%$ 左右. 2014- 2016 年间细沙百分含量小幅减小, 部分测点 $0.25 \mathrm{~mm}<d<0.36 \mathrm{~mm}$ 粒径组沙量已冲蚀殆尽, 导致 $0.36 \mathrm{~mm}<d<0.5 \mathrm{~mm}$ 粒径组泥沙占比相对增大. 泥沙平均中值粒径 $d_{50}$ 由 2014 年的 $0.216 \mathrm{~mm}$ 增大至 2016 年的 $0.237 \mathrm{~mm}$, 河床组成已呈现一定程度粗化. 由不同粒径下泥沙起动流速 (图 5) 可知,一般漫滩条件下滩面泥沙均可起动, $0.25 \mathrm{~mm}$ 和 $0.36 \mathrm{~mm}$ 这两种泥沙抗冲性相对较弱, 在滩体 $6 \mathrm{~m}$ 水深处起动流速约为 $0.45 \mathrm{~m} / \mathrm{s}$. 而颗粒越粗和越细的泥沙起动流速相对较大, 与细沙相比不易冲失, 这是因 为颗粒越粗的泥沙受重力作用较大, 极细沙及颗粒越细的泥沙分子间粘性作用较强, 在一定程度上均加大 了水流阻力, 抗拒水流紊动的作用较强, 导致其抗冲性相对较强 ${ }^{[20]}$. 由此可见, 河床组成中细沙含量是决定 洲滩抗冲性强弱的前提条件.

\section{2 水流过程的影响}

滩体演变与主流摆动关系密切, 不同流量下主流流路不同, 主流位置影响滩槽冲刷部位 ${ }^{[13]}$. 从图 6 可以 看出, 枯水流量下主流位于深槽内, 流速介于 $0.75 \sim 1.25 \mathrm{~m} / \mathrm{s}$, 滩体基本不过流. 流量增加后, 主流右摆至河 心, 边滩侧流速增大幅度比深槽处大. 随流量进一步增大, 边滩全部淹没于水面之下, 滩上断面平均流速约 
为 $1.2 \mathrm{~m} / \mathrm{s}$, 滩体左侧因靠近河心, 流速相对更大, 而细沙的泥沙起动流速在 $8 \mathrm{~m}$ 水深时仅为 $0.47 \mathrm{~m} / \mathrm{s}$ (图 5 ), 滩面泥沙易受水流冲刷, 脱离洲滩运动. 由流量大小变化可知,枯水流量下水流冲刷河槽, 而中洪水流量 时边滩受冲.

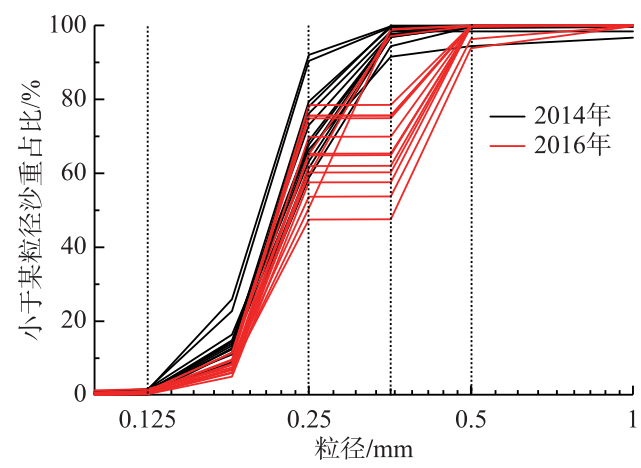

图 4 2014-2016 年 $2^{\#}$ 断面床沙级配变化

Fig.4 Transversal distribution of grain size of bed material of $2^{\#}$ cross section profile from 2014 to 2016

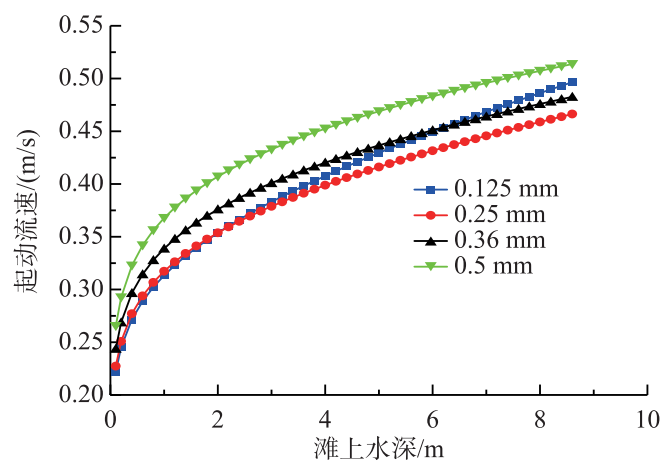

图 5 不同泥沙粒径下起动流速

Fig.5 Incipient velocity of different grain sizes of sediment

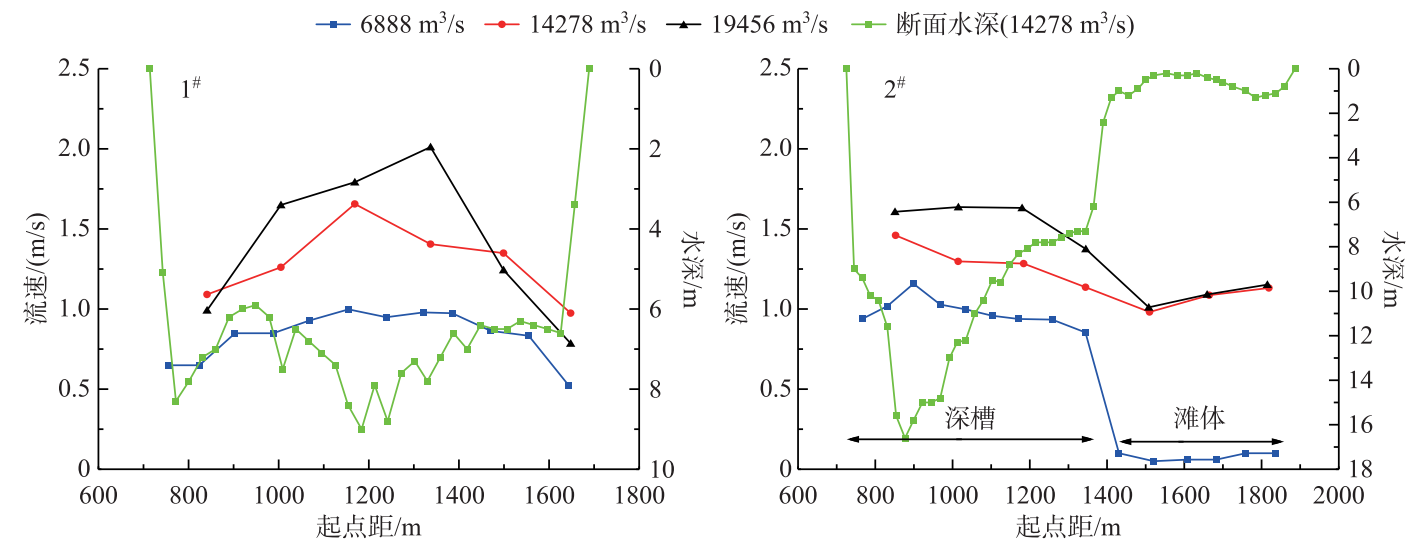

图 $61^{\#}$ 与 $2^{\#}$ 断面流速分布

Fig.6 Velocity distribution of $1^{\#}$ and $2^{\#}$ cross section profiles

当某一特征流量下的水位与边滩、心滩高程平齐 (平滩流量) 时, 对塑造洲滩形态起一定作用. 参照平滩 流量确定方法 ${ }^{[27]}$, 以监利站附近乌龟洲等几个典型断面历年平滩高程的平均值所对应的漫滩流量代表下荆 江河段众多滩体的漫滩流量, 因为同流量下乌龟洲及边滩漫滩时, 下荆江绝大多数滩体处于漫滩淹没状态, 其平滩高程平均值约为 31.54 m, 结合 2003-2016 年监利站水位与流量的关系 (图 7), 得到相应的漫滩流量 约为 $15000 \mathrm{~m}^{3} / \mathrm{s}$, 与马卡维耶夫法 $\left(Q^{\mathrm{m}} \mathrm{JP}\right)$ 计算得出的造床流量值 $16000 \mathrm{~m}^{3} / \mathrm{s}$ 相接近, 说明此漫滩流量对洲 滩及河床断面形态起一定的造床作用. 图 8 统计了 $15000 \mathrm{~m}^{3} / \mathrm{s}$ 流量下持续时间与边滩面积大小的关系, 可 以看出, 年内漫滩流量持续时间越长, 其对洲滩冲刷作用历时越长, 滩体面积一般变小, 而漫滩流量持续时 间越短, 滩体冲刷历时得不到保证, 面积反而增大. 然而 2009 年漫滩流量持续作用时间相对于其他年份较 少, 而滩体面积反而相对更小, 这说明漫滩流量持续时间并非影响滩体变化的决定性因素. 由于三峡水库 $175 \mathrm{~m}$ 试验性蓄水后, 流量坦化, 洪峰消减, 导致漫滩流量频率有所减少, 与此同时, 汛期来沙量也呈减少趋 势, 其对洲滩变形可能起主导作用. 


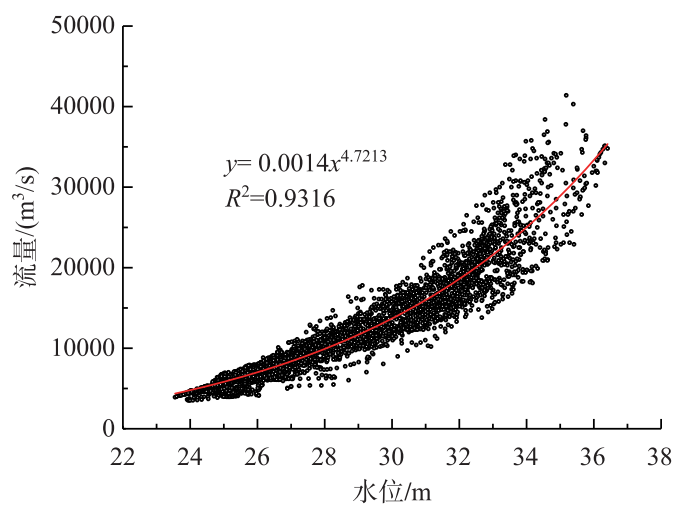

图 7 2003-2016 年监利站水位与流量的关系

Fig.7 Relationship between water level and discharge from 2003 to 2016 in Jianli Station

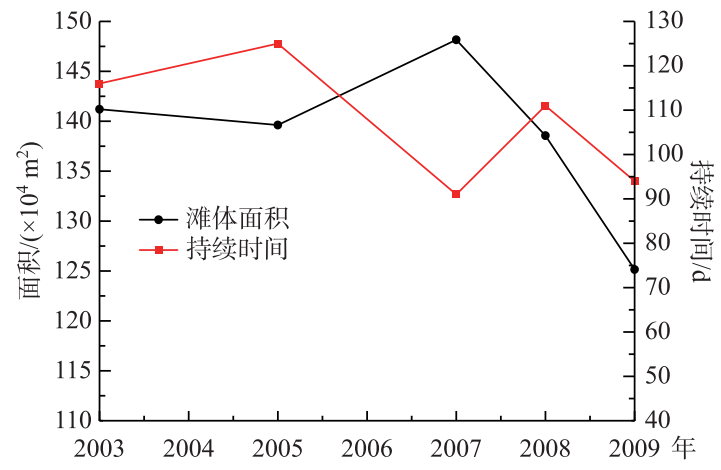

图 8 滩体面积变化与漫滩流量持续时间的关系

Fig.8 Relationship between point bar area and over-bar discharge duration

\section{3 来沙过程的影响}

4.3.1 讯期悬沙来量的影响 由边滩面积、滩长、最大滩宽与监利站汛期悬沙来量关系 (图 9) 可以看出, 面 积、滩长与汛期悬沙输沙量的相关性较好, 滩长和面积随汛期悬沙来量减少而减小. 最大滩宽和汛期悬沙来 量相关性较差, 这是因为边滩迎流冲刷整体向下游运移, 最大滩宽的位置也相应下移, 但其大小变化不明 显, 年际间有所波动. 三峡水库蓄水后, 年均汛期悬沙来量与蓄水前多年平均值 $3.23 \times 10^{8} \mathrm{t}$ 相比大幅减少, 汛 期锐减幅度更大, 滩体在漫滩水流冲刷后缺少回淤来源而冲刷萎缩. 2006 和 2011 年汛期悬沙来量均减小至 $0.32 \times 10^{8} \mathrm{t}$, 减幅达 $90.1 \%$, 占蓄水后其余年份均值 $0.85 \times 10^{8} \mathrm{t}$ 的 $37.6 \%$, 减幅相对更大, 因而相比之下, 滩体 萎缩程度更加明显.

4.3.2 悬沙级配下分组沙输移影响 三峡水库蓄水后, 监利站细沙、极细沙、粗粉沙总体均呈减少趋势, 中沙 整体表现为轻微增长, 中粉沙、细粉沙及黏土变化以 2008 年为分界点先减后增. 为进一步分析分组沙中哪 组沙量变化与滩体变化之间关系密切, 统计了监利站汛期各组悬沙来量与洲滩变形的可决系数 $R^{2}($ 表 2$)$, 发现细沙变化与滩体各特征参数拟合效果最好, 与面积和滩长的 $R^{2}$ 分别为 0.900 和 0.602 . 由上文可知, 洲 滩床沙级配多由细沙组成, 故本文选取汛期细沙来量进行重点分析, 如图 10 所示, 滩体面积及滩长随细沙 来量的增加而增大, 但最大滩宽相关性较差, 这是因为滩体向下运移时最大滩宽位置也相应发生了变化, 其 大小年际间上下波动.

表 2 汛期监利站分组输沙量与滩体特征参数的可决系数

Tab.2 The coefficient of determination between group sediment transport and characteristic parameters of point bar during flood season in Jianli Station

\begin{tabular}{cccccccc}
\hline 参数 & 细粉沙及黏土 & 中粉沙 & 粗粉沙 & 极细沙 & 细沙 & 中沙 & 粗沙、极粗沙 \\
\hline 面积 & 0.633 & 0.289 & 0.693 & 0.742 & 0.900 & 0.157 & 0 \\
滩长 & 0.446 & 0.120 & 0.476 & 0.357 & 0.602 & 0.024 & 0 \\
最大滩宽 & 0.084 & 0.083 & 0.022 & 0.244 & 0.007 & 0.501 & 0 \\
\hline
\end{tabular}

\section{4 水沙综合作用的影响}

为进一步分析水沙过程对洲滩演变的共同影响, 并考虑洲滩演变的滞后效应, 选取边滩面积与前 $N$ 年 漫滩流量下平均水流冲刷强度进行拟合, 由于 2006 年为特枯水文年, 漫滩流量历时仅为 $21 \mathrm{~d}$, 为其余年份均 值 $(100 \mathrm{~d})$ 的 $21 \%$, 且汛期来沙量锐减至 $0.32 \times 10^{8} \mathrm{t}$, 占其余年份均值 $\left(0.77 \times 10^{8} \mathrm{t}\right)$ 的 $41.6 \%$, 水沙过程影响程 度极不协调, 因而分析时未作考虑. 由图 11 可以看出, 边滩面积与前 3 年漫滩流量平均水流冲刷强度拟合 


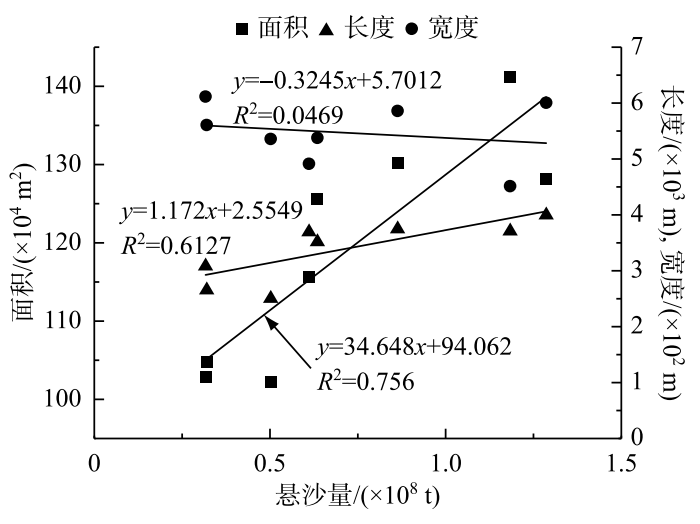

图 9 汛期悬沙来量与滩体特征值的相关关系

Fig.9 Correlation between the amount of suspended sediment in flood season and the characteristic value of point bar

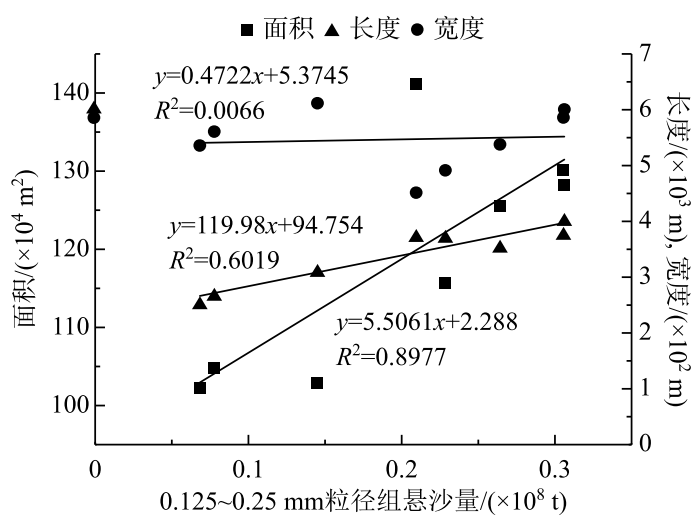

图 10 汛期细沙来量与滩体特征值的相关关系

Fig.10 Correlation between the amount of fine sediment in flood season and the

characteristic value of point bar

效果最好, $R^{2}=0.93,2003 、 2008$ 和 2013 年的漫滩流量平均水流冲刷强度分别为 11.69、16.45 和 20.94 , 其相 应面积分别为 $141.2 \times 10^{4} 、 125.56 \times 10^{4}$ 和 $102.2 \times 10^{4} \mathrm{~m}^{2}$ (表 3 ), 年际间漫滩流量平均水流冲刷强度逐渐增大, 与此同时边滩面积不断冲刷减少. 这是由于无守护工程时, 漫滩流量持续时间较长, 含沙量较小, 其平均水 流冲刷强度越大, 导致漫滩水流处于严重次饱和状态, 滩体越容易冲退萎缩.

\section{5 工程效应}

无守护工程时广兴洲边滩在水沙主导作用下呈冲刷萎缩趋势, 守护工程实施后, 滩体保持稳定且小幅 回淤 (图 12). 可见,航道整治工程能一定程度上影响洲滩冲淤变形,其作用有两个方面:一是改变局部河床 边界条件, 增强洲滩抗冲性, 二是改变局部水流结构和输沙调整. 航道整治工程能降低洲滩处流速, 减少次 饱和水流对洲滩细沙的篗取, 水流变缓导致泥沙落淤, 但限于悬沙来量较少, 洲滩呈微淤增长趋势. 综上可 知,近期广兴洲边滩冲淤变化是水沙条件及整治工程双重作用的结果.

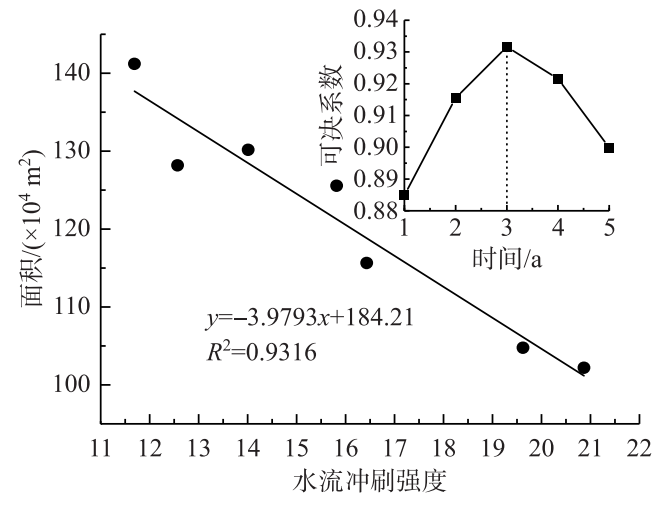

图 11 前 3 年漫滩流量平均水流冲刷强度与 滩体面积的关系及可决系数变化

Fig.11 Relationship and variation of determination coefficient between the average fluvial erosion intensity of over-bar discharge and point bar area in the first three years

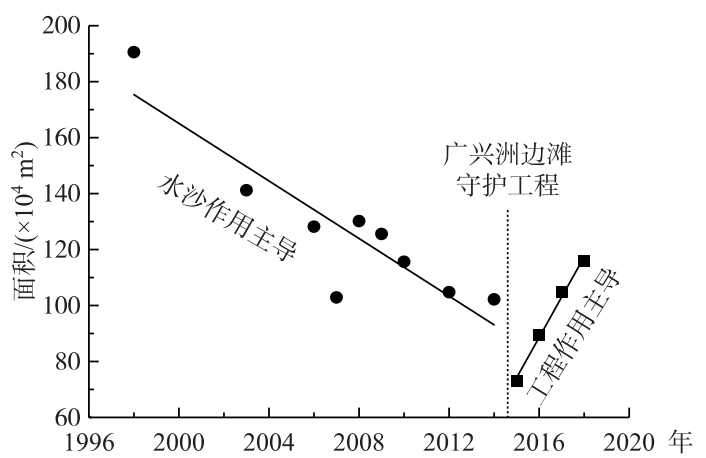

图 12 守护工程前、后 广兴洲边滩面积变化

Fig.12 Variation of Guangxingzhou point bar area before and after the revetment project 


\section{5 讨论}

三峡水库蓄水后各时段洲滩冲淤变形不同, 各因素影响程度有所差异, 表 3 统计了水沙因子表征参数 和滩体面积, 现以航道整治工程实施前后为例,初步分析各因素的影响程度.

边界条件中河床组成决定滩体的抗冲性强弱, 洲滩颗粒多由细沙组成, 抗冲性较弱, 是滩体冲刷的前提 条件.

为分析来沙量变化对洲滩形态的影响程度,选取 2009 和 2013 年做比较, 2013 年汗期径流量减少 $6.5 \%$, 漫滩流量历时减少 $2 \mathrm{~d}$, 与 2009 年流量过程较为相似, 而汛期细沙来量由 $0.23 \times 10^{8} \mathrm{t}$ 减至 $0.07 \times 10^{8} \mathrm{t}$, 减幅达 $69.6 \%$. 边滩面积由 $115.64 \times 10^{4} \mathrm{~m}^{2}$ 减少至 $102.2 \times 10^{4} \mathrm{~m}^{2}$, 萎缩率达 $11.6 \%$. 可见, 滩体面积随汛期细沙量减少 而减小, 且汛期细沙量减幅越大, 滩体萎缩越明显. 与其余年份相比, 2006 年属于小水小沙年, 漫滩流量持续 天数仅 $21 \mathrm{~d}$, 远小于其余年份均值 $(100 \mathrm{~d})$, 漫滩历时大幅减少, 但该年洲滩萎缩程度十分严重, 这是由细沙 来量大幅度减少导致的,进一步说明悬沙来量的减少是洲滩萎缩的主要原因.

为分析漫滩流量持续时间变化对洲滩形态的影响程度, 对比 2005 和 2007 年, 2007 年汛期细沙量均为 $0.31 \times 10^{8} \mathrm{t}$, 漫滩流量历时分别为 125 和 $91 \mathrm{~d}$, 降幅达 $27.2 \%$, 滩体面积反而增加 $1.99 \times 10^{4} \mathrm{~m}^{2}$, 增长了 $1.6 \%$. 再对比分析 2011 和 2013 年, 汛期细沙量分别为 $0.08 \times 10^{8}$ 和 $0.07 \times 10^{8} \mathrm{t}$, 量值基本变化不大, 而漫滩流量历时 分别为 74 和 $92 \mathrm{~d}$, 增幅达 $19.6 \%$, 洲滩减少了 $2.57 \times 10^{4} \mathrm{~m}^{2}$, 萎缩率仅达 $2.5 \%$. 可以看出, 漫滩流量历时增加 时, 滩体面积有所减少, 但变幅不大, 这说明漫滩流量持续时间对滩体变化有一定程度的影响, 与细沙量相 比,影响程度相对较小.

航道整治工程实施前, 水沙条件是影响洲滩变形的主要因素. 在漫滩水流长时间作用下, 洲滩迎头冲 刷,整体下移,同时面积变小. 汛期细沙来量为滩体提供沙源补充, 其大幅减少使得洲滩在漫滩水流冲刷后 淤积幅度变小. 滩体年内冲多淤少, 从而年际间冲退萎缩. 经过对比分析可知, 细沙来量贡献度比漫滩流量 持续时间更大. 因两者均有一定贡献度, 为了考虑水沙耦合作用, 以漫滩流量平均水流冲刷强度作为水流不 饱和程度的指标. 由表 3 可知,年际间漫滩流量平均冲刷强度不断增大, 由 2003 年的 11.69 逐渐增大至 2013 年的 20.94 , 导致水流不饱和程度不断加剧, 滩体冲刷萎缩严重. 航道整治工程实施后, 2016 年漫滩流量平均 水流冲刷强度仍然较大, 若无守护工程时滩体应呈冲退趋势, 然而滩体面积与 2014 年相比增加了 $40.8 \%$, 工 程作用占据主导地位. 这是因为工程改变了河床边界条件, 增加了河床的抗冲性, 同时降低了滩体处流速, 导致泥沙落淤.

表 3 水沙因子表征参数和滩体特征参数统计

Tab.3 Characteristic parameters of discharge, sediment and the point bar

\begin{tabular}{cccccccccccc}
\hline 指标 & 2003 年 & 2005 年 & 2006 年 & 2007 年 & 2008 年 & 2009 年 & 2011 年 & 2013 年 & 2014 年 & 2015 年 2016 年 \\
\hline 汛期流量 $/\left(\times 10^{8} \mathrm{~m}^{3}\right)$ & 2793 & 3000 & 1777 & 2741 & 2623 & 2582 & 2074 & 2415 & 2741 & 2343 & 2471 \\
漫滩流量历时 $/ \mathrm{d}$ & 116 & 125 & 21 & 91 & 111 & 94 & 74 & 92 & 116 & 91 & 88 \\
汛期细沙量 $/\left(\times 10^{8} \mathrm{t}\right)$ & 0.21 & 0.31 & 0.15 & 0.31 & 0.26 & 0.23 & 0.08 & 0.07 & 0.10 & 0.08 & - \\
漫滩流量平均水流冲刷强度 $\left(F_{\mathrm{T}}\right)$ & 11.69 & 12.96 & 10.01 & 16.17 & 16.45 & 16.72 & 17.47 & 20.94 & 26.37 & 26.26 & 42.91 \\
滩体面积 $/\left(\times 10^{4} \mathrm{~m}^{2}\right)$ & 141.2 & 128.18 & 102.88 & 130.17 & 125.56 & 115.64 & 104.77 & 102.2 & 73.02 & 86.06 & 102.82 \\
\hline
\end{tabular}

\section{6 结论}

1) 三峡水库蓄水后, 下荆江沙质河段边心滩普遍冲刷萎缩, 广兴洲边滩作为典型顺直边滩, 年际间冲刷 下移,变化幅度较大, 至 2014 年 2 月滩体面积减少了 $39 \times 10^{4} \mathrm{~m}^{2}$, 萎缩率达 $38.2 \%$, 滩头年均冲退 $113 \mathrm{~m}$. 航 道整治工程实施后, 滩体有所微淤, 至 2017 年 3 月面积增加至 $102.82 \times 10^{4} \mathrm{~m}^{2}$, 滩头上移 $576 \mathrm{~m}$.

2)下荆江河段洲滩河床多由细沙组成, 导致滩体抗冲性较弱, 此为不饱和水流冲刷的先决条件. 其次, 水动力条件对下荆江河段洲滩冲淤变形有一定影响, 漫滩流量 $\left(Q>15000 \mathrm{~m}^{3} / \mathrm{s}\right)$ 上滩后, 持续作用时间变长, 滩体一般表现为冲刷后退, 面积变小. 悬移质细沙量为洲滩提供沙源补充, 汛期悬移质分组沙输移过程中, 
细沙 $(0.125 \mathrm{~mm}<d<0.25 \mathrm{~mm})$ 的减少导致滩体受漫滩水流冲刷后, 缺乏回淤来源而呈冲退萎缩趋势.

3 ) 通过水沙单因素变量对比分析,细沙来量相较于漫滩水流持续时间,对洲滩变形程度的影响更大. 漫 滩水流历时相近, 细沙量减幅越大时, 滩体萎缩率越大. 当汛期细沙来量基本相同时, 漫滩流量历时增加, 滩 体特征参数有所减少, 但变幅不大.

4 ) 在水沙耦合机理上, 滩体面积与前 3 年漫滩流量 $\left(Q>15000 \mathrm{~m}^{3} / \mathrm{s}\right)$ 平均水流冲刷强度拟合效果最好, 水流冲刷强度越大时, 水流不饱和程度加剧, 则滩体面积越小. 航道整治工程实施后, 漫滩流量平均水流冲 刷强度仍然较大, 但滩体稳定且微淤上移, 说明工程作用占据主导地位. 这将对揭示下荆江河段洲滩演变规 律和机理以及发挥航道整治工程效果具有重要参考价值.

\section{7 参考文献}

[ 1 ] Xu QX. Research on reservoir sedimentation and downstream channel erosion of dam after impoundment of Three Gorges Reservoir. Yangtze River, 2012, 43(7) : 1-6. [许全喜. 三峡水库蓄水以来水库淤积和坝下冲刷研究. 人民长江, $2012,43(7): 1-6$.

[ 2 ] Xue XH, Chang S, Song EP. Evolution of floodplains and bars at the Jingjiang reach of Yangtze River, China in response to Three Gorges Reservoir impoundment. Acta Geographica Sinica, 2018, 73(9) : 1714-1727. DOI: 10.11821/dlxb201809008. [薛兴华, 常胜, 宋鄂平. 三峡水库蓄水后荆江洲滩变化特征. 地理学报, 2018, 73(9): 1714-1727.]

[ 3 ] Wang J, Dai ZJ, Mei XF et al. Immediately downstream effects of Three Gorges Dam on channel sandbars morphodynamics between Yichang-Chenglingji Reach of the Changjiang River, China. Journal of Geographical Sciences, 2018, 28 ( 5 ) : 629-646. DOI: 10.1007/s11442-018-1495-8.

[ 4 ] Jiang L, Li YT, Sun ZH et al. Channel evolution of Jingjiang reach and its influences on waterway after impoundment of the Three Gorges Project. Journal of Basic Science and Engineering, 2010, 18(1): 1-10. [江凌, 李义天, 孙昭华等. 三 峡工程蓄水后荆江沙质河段河床演变及对航道的影响. 应用基础与工程科学学报, 2010, 18(1): 1-10.]

[ 5 ] Zhu LL, Xu QX, Chen ZH. Extraordinary scour of Jingjiang reach downstream from Three Gorges Project. Journal of Basic Science and Engineering, 2018, 26(1): 85-97. [ 朱玲玲, 许全喜, 陈子寒. 新水沙条件下荆江河段强冲刷响应研究. 应用基础与工程科学学报, 2018, 26(1):85-97.]

[ 6 ] Zhu LL, Ge H, Li YT et al. Branching channels in the middle Yangtze River, China. Journal of Basic Science and Engineering, 2015, 23(2): 246-258. [ 朱玲玲, 葛华, 李义天等. 三峡水库蓄水后长江中游分汉河道演变机理及趋势. 应用基础与工程科学学报, $2015, \mathbf{2 3}(2): 246-258$. $]$

[ 7 ] Raška P, Dolejš M, Hofmanová M. Effects of damming on long-term development of fluvial Islands, Elbe river ( $N$ czechia). River Research and Applications, 2017, 33(4) : 471-482. DOI: 10.1002/rra.3104.

[ 8 ] Kiss T, Balogh M. Characteristics of point-bar development under the influence of a dam: Case study on the dráva river at sigetec, croatia. Journal of Environmental Geography, 2015, 8(1/2) : 23-30. DOI: 10.1515/jengeo-2015-0003.

[ 9 ] Han QW, Tong ZJ. Characteristics and mechanism of branching river channel in the downstream watercourse of Danjiangkou Reservoir. Yangtze River, 1986, 17(3) : 26-32. [韩其为, 童中均. 丹江口水库下游分汉河道河床演变特点及机 理. 人民长江, 1986, 17(3) : 26-32.]

[10] Duan GL, Peng YB, Xiao HC et al. Preliminary probe into evolvement mechanism of typical shoals at Jingjiang reach of Yangtze River. Hydro-Science and Engineering, 2008, (2): 10-15. [段光否, 彭严波, 肖虎程等. 长江荆江河段典型 洲滩演变机理初探. 水利水运工程学报, 2008, (2): 10-15.]

[11] Sun ZH, Feng QF, Han JQ et al. Fluvial processes of sandbars in the junction reach of single-threaded channel to anabranching channel and its impact on navigation: A case study of the Tianxingzhou Reach of the Yangtze River. Journal of Basic Science and Engineering, 2013, 21(4) : 647-656. [孙昭华, 冯秋芬, 韩剑桥等. 顺直河型与分汉河型交界段洲 滩演变及其对航道条件影响——长江天兴洲河段为例. 应用基础与工程科学学报, 2013, 21(4): 647-656.]

[12] Zou SL, Guo C, Liu XP. Evaluation on the impacts of environmental changes and Three-Gorge Engineering on the population of Yangtze voles (Microtus forits) in the Dongting Lake region. Chinese Journal of Applied Ecology, 2002, 13(5): 585-588. [邹郡林, 郭聪, 刘新平. 环境演变及三峡工程对洞庭湖区东方田鼠种群影响的评估. 应用生态学报, $2002, \mathbf{1 3}(5): 585-588$.

[13] Li YT, Tang JW, Zhu LL ed eds. Channel evolution and regulation in the middle and lower reaches of the Yangtze River. 
Beijing: Science Press, 2012. [李义天, 唐金武, 朱玲玲等. 长江中下游河道演变与航道整治. 北京: 科学出版 社. 2012.]

[14] Zhu LL, Ge H. Recent fluvial processes of typical braided channel in upper Jingiiang reach. Journal of Sediment Research, 2016, (2) : 33-39. [ 朱玲玲, 葛华. 三峡水库 175m 蓄水后荆江典型分汉河段演变趋势预测. 泥沙研究, 2016, (2) : 33-39.]

[15] Han JQ, Sun ZH, Feng QF. Critical features of flow dynamics at the entrance of multi-branched channels. Advances in Water Science, 2013, 24(6): 842-848. [ 韩剑桥, 孙昭华, 冯秋芬. 江心洲头部冲淤动力临界特性. 水科学进展, 2013, 24(6): 842-848.]

[16] Zhao L, Li YT, Sun ZH. Preliminary study of impact of water and sediment transport process on bars in Daorenji-Yanglinyan straight braided reach. Journal of Sediment Research, 2013, (4):26-33. [赵琳, 李义天, 孙昭华. 水沙过程对道 人矶-杨林岩顺直分汊河段洲滩演变影响初步研究. 泥沙研究, 2013, (4) : 26-33.]

[17] Li ZW, Li YF, Wang ZY et al. A conceptual model of deposition and erosion of mid-channel bar head zone in Anabranching River. Advances in Water Science, 2016, 27(1): 1-10. [李志威, 李艳富, 王兆印等. 分汉河流江心洲洲头冲淤 概化模型. 水科学进展, 2016, 27(1): 1-10.]

[18] Lou YY, Mei XF, Dai ZJ et al. Evolution of the mid-channel bars in the middle and lower reaches of the Changjiang ( Yangtze) River from 1989 to 2014 based on the Landsat satellite images: Impact of the Three Gorges Dam. Environmental Earth Sciences, 2018, 77(10) : 394. DOI: 10.1007/s12665-018-7576-2.

[19] Lane EW. Report of the subcommittee on sediment terminology. Eos, Transactions American Geophysical Union, 1947,28 (6) : 936-938. DOI: 10.1029/TR028i006p00936.

[20] Zhang RJ ed. River sediment dynamics. Beijing: Water Resources and Electric Power Press, 1989. [张瑞瑾. 河流泥沙动 力学. 北京: 水利电力出版社, 1989.]

[21] Xia JQ, Deng SS, Lu JY et al. Dynamic channel adjustments in the Jingjiang reach of the middle Yangtze River. Scientific Reports, 2016, 6: 22802. DOI: 10.1038/srep22802.

[22] Wu BS. Delayed response model for fluvial processes of alluvial rivers- I model development. Journal of Sediment Research, 2008, (6) : 1-7. [ 吴保生. 冲积河流河床演变的滞后响应模型- I 模型建立. 泥沙研究, 2008, (6) : 1-7.]

[23] Sun QH, Xia JQ, Zhou MR et al. Characteristics of channel adjustments and bank erosion in the Chenghan reach after the Three Gorges Project operation. J Lake Sci, 2019, 31(5) : 1447-1458. DOI: 10.18307/2019.0526. [孙启航, 夏军强, 周美蓉等. 三峡工程运用后城陵矶-武汉河段河床调整及崩岸特点. 湖泊科学, 2019, 31(5): 1447-1458. ]

[24] Guo XH, Qu G, Liu Y et al. Sediment transport of different particle size groups in the downstream channel after operation of the Three Gorges Project. J Lake Sci, 2020, 32(2) : 564-572. DOI: 10.18307/2020.0226. [郭小虎, 渠庚, 刘亚等. 三峡工程运用后坝下游河道泥沙输移变化规律. 湖泊科学, 2020, 32(2) : 564-572.]

[25] Xia JQ, Zong QL, Xu QX et al. Soil properties and erosion mechanisms of composite riverbanks in Lower Jingjiang Reach. Advances in Water Science, 2013, 24(6): 810-820. [夏军强, 宗全利, 许全喜等. 下荆江二元结构河岸土体特性及 崩岸机理. 水科学进展, 2013, 24(6): 810-820.]

[26] Zhu LL, Xu QX, Xiong M. Fluvial processes of meandering channels in the Lower Jingjiang River reach after the impoundment of Three Gorges Reservoir. Advances in Water Science, 2017, 28(2): 193-202. [ 朱玲玲, 许全喜, 熊明. 三峡水库 蓄水后下荆江急弯河道凸冲凹淤成因. 水科学进展, 2017, 28(2) : 193-202.]

[27] Zhang W, Gao Y, Xu QX et al. Changes in dominant discharge and their influential factors in the middle and lower reaches of Yangtze River after the Three Gorges Dam impoundment. Advances in Water Science, 2018, 29(3) : 331-338. [张为, 高宇, 许全喜等. 三峡水库运用后长江中下游造床流量变化及其影响因素. 水科学进展, 2018, 29(3): 331-338.] 